\title{
EDITORIAL
}

\section{La CoP de París}

La $21^{\text {a }}$ Conferència de les Parts del Conveni Marc de les Nacions Unides sobre el Canvi Climàtic i la $11^{a}$ Reunió de les Parts al Protocol de Kyoto es van celebrar al desembre de 2015 a París, amb l'objectiu d'aconseguir un acord universal i jurídicament vinculant per reduir les emissions de gasos d'efecte hivernacle i limitar així l'augment de la temperatura global del planeta a $2^{\circ} \mathrm{C}$ respecte dels nivells preindustrials.

La Conferència de París és la culminació d'un llarg procés de negociació per renovar els compromisos assumits el 1997. El règim internacional del canvi climàtic ha anat evolucionant al llarg de diverses etapes, entre les quals cal destacar un primer període de caràcter constituent, des dels anys vuitanta fins 1995, que resulta en l'adopció del Conveni Marc i la seva entrada en vigor; i una segona fase de regulació, entre 1995 i 2005, que inclou la negociació, adopció, i entrada en vigor del Protocol de Kyoto. En aquests primers quinze anys els principals actors d'aquest règim internacional han estat sens dubte la Unió Europea i els Estats Units, tots dos amb posicions antagòniques i amb un clar lideratge de la primera. Des de 2005 la situació ha anat canviant diametralment, amb la pèrdua progressiva de rellevància de la Unió Europea i l'emergència dels països del grup BASIC (Brasil, Índia, Xina i Sudàfrica) en les negociacions. L'epicentre d'aquesta darrera etapa comprèn la negociació del règim "post-Kyoto" a partir de 2007, inclòs el fracàs de la Conferència de Copenhaguen el 2009, la formalització el 2012 de l'acord respecte al segon període de compromís (2013-2020) mitjançant una esmena que encara no ha entrat en vigor i la conclusió de l’Acord adoptat a París el desembre de 2015.

Al llarg de tot aquest procés, i especialment en el moment de la negociació de l'Acord de París, les posicions de les parts han estat molt condicionades pel debat sobre l'abast de l'obligació de diferenciació entre els anomenats països de l'annex I i els països que no hi son, i la seva aplicació d'acord amb les circumstàncies i capacitats nacionals dels Estats Part. La Unió Europea, juntament amb altres Estats europeus no membres, ha defensat tradicionalment importants reduccions en els nivells d'emissions de gasos d'efecte hivernacle dels països industrialitzats, alhora que ha promogut una acció mesurable en els països en desenvolupament i l'adopció de mesures d'adaptació 
mitjançant l'establiment de mesures comunes. Els països del grup Paraigües (Japó, Canadà, Austràlia, Noruega, Nova Zelanda, Federació Russa, a més dels Estats Units, als quals ocasionalment es sumen Kazakhstan i Ucraïna) tenen en comú el seu interès per una estratègia més "flexible" que limiti les emissions (objectius i calendaris no obligatoris, instruments de mercat). Els països del grup BASIC s'han compromès amb la realització de certes accions de mitigació de les emissions, però s'oposen clarament a l'assumpció no diferenciada de compromisos jurídicament vinculants de reducció. El Grup G-77 comprèn una coalició de 133 països molt diversa que tenen en comú un interès en la fixació dels compromisos de reduccions d'emissions dels països desenvolupats $\mathrm{i}$ de transferències financeres i tecnològiques sobre la base del principi de les responsabilitats comunes però diferenciades. L'Aliança de Petits Estats Insulars en Desenvolupament integra 39 països (membres del G-77) particularment vulnerables al canvi climàtic, per la qual cosa són especialment proactius en les negociacions, i defensen les posicions més ambicioses. Finalment, als membres de l'Organització dels Països Exportadors de Petroli els preocupen essencialment les conseqüències que sobre les seves economies podria tenir el fet que els altres països reduïssin el consum de petroli.

L'Acord adoptat a París el passat desembre ha estat considerat, entre d'altres qualificatius, de "triomf monumental" i "d'èxit clamorós del multilateralisme", en paraules del Secretari General de les Nacions Unides, Ban-ki-moon. La Unió Europea l'ha valorat també com un "acord històric", que satisfà les seves exigències pel que fa als tres grans eixos de la seva política de canvi climàtic (ambició, compromís i solidaritat). Ara bé, més enllà d'un clar i rotund èxit polític i mediàtic, ¿què és el que realment s'ha acordat a París?, ¿fins a quin punt aquest Acord permet determinar el nivell de compromís real de la comunitat internacional respecte la lluita contra el canvi climàtic?

Certament, el context que envoltava a la Conferència de París no era el mateix que va portar a finals dels anys noranta a subscriure de manera entusiasta el Protocol de Kyoto. De fet, des de la seva entrada en vigor el 2005 tot el procés ha estat llastrat per la falta de suport i de confiança entre les Parts. Aquesta situació es va agreujar des de la Conferència de Copenhaguen el 2009, clar reflex de les tensions existents i del tomb que es va produir en les negociacions sobre el règim multilateral del canvi climàtic. El fracàs de Copenhaguen va estar molt present a París i les Parts, i molt especialment la 
presidència francesa, van esmerçar esforços per evitar un nou fiasco, que hagués estat inadmissible en les circumstàncies actuals. Per tant, s'havia de posar en valor qualsevol resultat, per petit que fos, que assolís la Conferència, i això ha portat potser a una valoració positiva en excés.

D'una banda, és cert que s'han superat dos grans reptes que tenia davant seu la Conferència. El primer era adoptar un instrument jurídicament vinculant, universal i diferenciat. El mateix procés de la Plataforma de Durban ja imposava algunes limitacions pel que fa a la naturalesa de l'instrument resultant de la negociació, a l'exigir l'adopció d'un acord obligatori per les Parts. L'adopció d'una decisió de la Conferència de les Parts per la qual s'aprova l'Acord de París en virtut de la Convenció Marc de les Nacions Unides sobre el Canvi Climàtic (FCCC / CP / 2015 / L .9 / Rev.1) constitueix doncs un pas molt important $i$ enforteix sens dubte el règim multilateral del canvi climàtic. Ara bé, no es pot ignorar que, tot i tractant-se d'un acord multilateral, i per tant, d'un instrument formalment jurídicament vinculant per a les Parts, l'Acord de París conté elements importants que manquen clarament d'aquest efecte obligatori, entre ells un de tan essencial com el de l'establiment d'objectius de reducció d'emissions individuals.

També sembla superat el segon repte de la Conferència: reconduir l'oposició d'alguns dels principals actors en l'escena internacional i, molt especialment, trobar la forma de què els Estats Units i d'altres Estats, com Canadà, Japó, la Federació Russa, o els països del grup BASIC, abandonessin les seves reticències i es sumessin al consens general. Tot $\mathrm{i}$ que aquests Estats segueixen propiciant aliances de compliment voluntari fora del marc convencional multilateral, finalment s'han alineat al voltant d'una interpretació flexible del concepte de diferenciació que permet la seva permanència dins el sistema. A més, més enllà de l'eficàcia de la diplomàcia francesa al llarg de la negociació, i molt especialment, de la rellevància que va tenir en l'última fase de la Conferència el Comitè de París, no pot negar-se el paper clau dels Estats Units, la Xina i l'Índia per facilitar l'acord, assumint certs compromisos per reduir les seves pròpies emissions de gasos d'efecte hivernacle.

En canvi, si ens fixem en el contingut del que s'ha acordat, 1'ampolla sembla, malauradament, mig buida. Pel que fa a la mitigació, l'acord exigeix que les Parts actuïn per reduir les seves emissions de gasos d'efecte hivernacle $i$ arribin al màxim d'emissions "com més aviat possible" per continuar a partir d'aleshores amb les 
reduccions a mesura que avança el segle. En termes generals, es fixa l'objectiu de limitar l'augment de la temperatura fins a l'any 2100 en $2^{\circ} \mathrm{C}$ respecte als nivells preindustrials. No obstant això, l'acord deixa un marge considerable als Estats per determinar com $\mathrm{i}$ on duen a terme aquestes reduccions i només requereix que informin de manera transparent dels esforços realitzats. De fet, conforme al plantejament bottomup del nou instrument i a diferència del Protocol de Kyoto, l'acord no inclou objectius quantificats de reducció específics, jurídicament vinculants pels Estats. Ans al contrari, les Parts han de demostrar que el compromís de reducció de les emissions que proposen i assumeixen (Contribucions Determinades a Nivell Nacional - INDCs) constitueix una contribució justa a l'esforç global de reducció, una valoració que s'acompanya d'un procés d'avaluació i revisió tècnica independent cada cinc anys.

D'altra banda, i per primera vegada en les negociacions sobre canvi climàtic, les qüestions relatives a l'adaptació han tingut una importància similar a la que tenen tradicionalment els aspectes vinculats amb la mitigació. Segurament això es deu a que molts dels INDCs presentats pels Estats incloïen els objectius i les prioritats d'adaptació juntament $\mathrm{amb}$ els objectius de reducció d'emissions. En aquest àmbit l'acord persegueix un objectiu global de "millorar la capacitat d'adaptació, l'enfortiment de la resiliència $\mathrm{i}$ reduir la vulnerabilitat al canvi climàtic per tal de contribuir al desenvolupament sostenible i assegurar una resposta adequada d'adaptació en el context de la meta de temperatura". L'acord vincula així, explícitament, l'adaptació i la mitigació i encoratja a les Parts a informar d'aquestes accions també en períodes de cinc anys, però de nou utilitza una redacció excessivament genèrica pel que fa a la planificació i la implementació de les mesures d'adaptació. D’altra banda, es tracta de manera diferenciada el Mecanisme Internacional de Varsòvia per les Pèrdues i els Danys relacionats amb les Repercussions del Canvi Climàtic (especialment els esdeveniments provocats tant pels fenòmens extrems com pels fenòmens d'evolució lenta), però de nou queda per al futur el desenvolupament de les seves funcions, modalitats i procediments. I més important encara, d'acord amb la Decisió de la COP, s'exclouen les qüestions relacionades amb la responsabilitat internacional o la indemnització (par. 52).

A tall de conclusió es pot considerar que des del fracàs que va suposar la Conferència de Copenhaguen el 2009 hem assistit, al llarg de les successives reunions, a un important esforç per anar restaurant la confiança de les Parts al Conveni Marc en el procés 
multilateral per a l'establiment del règim internacional de canvi climàtic iniciat el 1992. En aquesta línia, la Conferència de París ha constituït un nou punt d'inflexió. La conclusió favorable d'un instrument internacional que renovi els compromisos subscrits a Kyoto el 1997 i que sigui jurídicament vinculant és un gran pas per a la comunitat internacional. Ara bé, el pragmatisme ha prevalgut sobre les grans expectatives, i allà on semblava difícil assolir una acció concertada de caràcter multilateral, s'han imposat, sota el mantell del principi de les responsabilitats comunes però diferenciades i la consideració de les circumstàncies nacionals, les solucions més conformes amb els interessos geoestratègics dels Estats més influents en el procés de negociació, en aquest moment els Estats Units i els països del grup BASIC. Un acord doncs, que difereix dels seus antecessors pel seu abast limitat, que fia al futur i a l'acció dels Estats i en menys mesura de la Conferència de les Parts com assolir la limitació dels $2^{\mathrm{a}} \mathrm{C}$, i que en definitiva s'explica segurament per la pèrdua d'influència de la Unió Europea, l'emergència en el context de les negociacions dels països del grup BASIC i la recuperació de la iniciativa per part dels Estats Units. 


\section{EDITORIAL}

\section{La CoP de París}

La 21 ${ }^{\mathrm{a}}$. Conferencia de las Partes del Convenio Marco de Naciones Unidas sobre el Cambio Climático y la 11 ${ }^{\text {a }}$. Reunión de las Partes al Protocolo de Kioto se celebraron en diciembre de 2015 en París, con el objetivo de conseguir un acuerdo universal y jurídicamente vinculante para reducir las emisiones de gases de efecto invernadero y limitar así el aumento de la temperatura global del planeta a $2^{\circ} \mathrm{C}$ respecto a los niveles preindustriales.

La Conferencia de París ha sido la culminación de un largo proceso de negociación para renovar los compromisos asumidos en 1997. El régimen internacional del cambio climático ha ido evolucionando a lo largo de diferentes etapas, entre las que debe destacarse un primer período de carácter constituyente, desde los años ochenta hasta 1995, que resulta en la adopción del Convenio Marco y su entrada en vigor; y una segunda fase de regulación, entre 1995 y 2005, que incluye la negociación, adopción y entrada en vigor del Protocolo de Kioto. En estos primeros quince años, los principales actores de este régimen internacional han sido sin duda la Unión Europea y Estados Unidos, ambos con posiciones antagónicas y un claro liderazgo de la primera. Desde 2005, la situación ha ido cambiando diametralmente, con la pérdida progresiva de relevancia de la Unión Europea y la emergencia de los países del grupo BASIC (Brasil, India, China y Sudáfrica) en las negociaciones. El epicentro de esta última etapa comprende la negociación del régimen "post-Kioto" a partir de 2007, incluso el fracaso de la Conferencia de Copenhague en 2009, la formalización del acuerdo respecto al segundo período de compromiso (2013-2020) mediante una enmienda que aún no ha entrado en vigor y la conclusión del Acuerdo adoptado en París en diciembre.

A lo largo de todo este proceso y, especialmente, en el momento de la negociación del Acuerdo de París, las posiciones de las partes han estado muy condicionadas por el debate sobre el alcance de la obligación de diferenciación entre los llamados países del anexo I y los países que no figuran en él, y su aplicación de acuerdo con las circunstancias y las capacidades nacionales de los Estados Parte. La Unión Europea, junto con otros Estados europeos no miembros, ha defendido tradicionalmente importantes reducciones en los niveles de emisiones de gases de efecto invernadero de 
los países industrializados, al mismo tiempo que ha promovido una acción mensurable en los países en vías de desarrollo y la adopción de medidas de adaptación mediante el establecimiento de medidas comunes. Los países del grupo Paraguas (Japón, Canadá, Australia, Noruega, Nueva Zelanda, Federación Rusa, además de Estados Unidos, a los que se suman ocasionalmente Kazajstán y Ucrania) tienen en común su interés por una estrategia más "flexible" que limite las emisiones (objetivos y calendarios no obligatorios, instrumentos de mercado). Los países del grupo BASIC se han comprometido con la realización de ciertas acciones de mitigación de las emisiones, pero se oponen claramente a la asunción no diferenciada de compromisos jurídicamente vinculantes de reducción. El Grupo G-77 comprende una coalición de 133 países muy diversa que tienen en común un interés en la fijación de los compromisos de reducción de emisiones de los países desarrollados y de transferencias financieras y tecnológicas sobre la base del principio de responsabilidades comunes pero diferenciadas. La Alianza de Pequeños Estados Insulares en Desarrollo integra 39 países (miembros del G-77) particularmente vulnerables al cambio climático, por lo cual son especialmente proactivos en las negociaciones y defienden las posiciones más ambiciosas. Finalmente, los miembros de la Organización de los Países Exportadores de Petróleo están preocupados, esencialmente, por las consecuencias que sobre sus economías podría tener el hecho de que otros países redujeran el consumo de petróleo.

El Acuerdo adoptado en París el pasado diciembre ha sido considerado entre otros calificativos, de "triunfo monumental" y de "éxito clamoroso del multilateralismo", en palabras del Secretario General de Naciones Unidas, Ban-ki-moon. La Unión Europea lo ha valorado también como un "acuerdo histórico", que satisface sus exigencias en relación con los tres grandes ejes de su política de cambio climático (ambición, compromiso y solidaridad). Ahora bien, más allá de un claro y rotundo éxito político y mediático, ¿Qué es lo que realmente se ha acordado en París? ¿hasta qué punto este Acuerdo permite determinar el nivel de compromiso real de la comunidad internacional respecto a la lucha contra el cambio climático?

Ciertamente, el contexto que rodeaba a la Conferencia de París no era el mismo que llevó a finales de los noventa a suscribir de manera entusiasta el Protocolo de Kioto. De hecho, desde su entrada en vigor en 2005 todo el proceso ha estado lastrado por la falta de apoyo y de confianza entre las Partes. Esta situación se agravó desde la Conferencia de Copenhague en 2009, claro reflejo de las tensiones existentes y del giro que se 
produjo en las negociaciones sobre el régimen multilateral del cambio climático. El fracaso de Copenhague estuvo muy presente en París y las Partes, muy especialmente la presidencia francesa, consumieron esfuerzos para evitar un nuevo fiasco, que hubiera sido inadmisible en las circunstancias actuales. Por lo tanto, debía de ponerse en valor cualquier resultado, por pequeño que fuera, que se lograse en la Conferencia, y esto ha llevado quizá a una valoración positiva en exceso.

Por una parte, es cierto que se han superado dos grandes retos que tenía ante sí la Conferencia. El primero era adoptar un instrumento jurídicamente vinculante, universal y diferenciado. El mismo proceso de la Plataforma de Durban ya imponía algunas limitaciones en relación con la naturaleza del instrumento resultante de la negociación, al exigir la adopción de un acuerdo obligatoria para las Partes. La adopción de una decisión de la Conferencia de las Partes por la que se aprueba el Acuerdo de París en virtud de la Convención Marco de Naciones Unidas sobre el Cambio Climático (FCCC / CP / 2015 / L .9 / Rev.1) constituye así un paso muy importante y fortalece sin duda el régimen multilateral del cambio climático. Ahora bien, no puede ignorarse que, a pesar de tratarse de un acuerdo multilateral, y por lo tanto, de un instrumento formalmente vinculante desde el punto de vista jurídico para las Partes, el Acuerdo de París contiene importantes elementos que adolecen de falta de tal efecto obligatorio, entre los que cabe mencionar uno tan esencial como el del establecimiento de objetivos de reducción de emisiones individuales.

También parece superado el segundo reto de la Conferencia: reconducir la oposición de algunos de los principales actores en la escena internacional y, muy especialmente, encontrar la forma de que Estados Unidos y otros Estados, como Canadá, Japón, la Federación Rusa o los países del grupo BASIC, abandonaran sus reticencias y se sumaran al consenso general. Aunque estos Estados siguen propiciando alianzas de cumplimiento voluntario fuera del marco convencional multilateral, finalmente se han alineado alrededor de una interpretación flexible del concepto de diferenciación que permite su permanencia en el sistema. Además, más allá de la eficacia de la diplomacia francesa a lo largo de la negociación y, muy espacialmente, de la relevancia que tuvo en la última fase de la Conferencia el Comité de París, no puede negarse el papel clave de Estados Unidos, China e India para facilitar el acuerdo, asumiendo ciertos compromisos para reducir sus propias emisiones de gases de efecto invernadero. 
En cambio, si nos fijamos en el contenido de lo que se ha acordado, la botella parece, desgraciadamente, medio vacía. En relación con la mitigación, el acuerdo exige que las Partes actúen para reducir sus emisiones de gases de efecto invernadero y lleguen al máximo de emisiones "lo más pronto posible" para continuar, a partir de entonces, con las reducciones a medida que avanza el siglo. En términos generales, se fija el objetivo de limitar el aumento de temperatura hasta el año 2100 en $2^{\circ} \mathrm{C}$ respecto a los niveles preindustriales. No obstante, el acuerdo deja un margen considerable a los Estados para determinar cómo y dónde llevan a cabo estas reducciones y sólo requiere que informen de manera transparente de los esfuerzos realizados. De hecho, conforme al planteamiento bottom-up del nuevo instrumento y a diferencia del Protocolo de Kioto, el acuerdo no incluye objetivos cuantificados de reducción específicos, jurídicamente vinculantes para los Estados. Más bien al contrario, las Partes deben demostrar que el compromiso de reducción de las emisiones que proponen y asumen (Contribuciones Determinadas a Nivel Nacional - INDCs) constituyen una contribución justa al esfuerzo global de reducción, una valoración que se acompaña de un proceso de evaluación y revisión técnica independiente cada cinco años.

Por otra parte, y por primera vez en las negociaciones sobre el cambio climático, las cuestiones relativas a la adaptación han tenido una importancia similar a la que tienen tradicionalmente los aspectos vinculados a la mitigación. Seguramente, esto se debe a que muchos de los INDCs presentados por los Estados incluyen los objetivos y las prioridades de adaptación junto con los objetivos de reducción de emisiones. En este ámbito el acuerdo persigue un objetivo global de "mejorar la capacidad de adaptación, el fortalecimiento de la resiliencia y reducir la vulnerabilidad al cambio climático para contribuir al desarrollo sostenible y asegurar una respuesta adecuada de adaptación en el contexto de la meta de temperatura”. El acuerdo vincula así, explícitamente, la adaptación y la mitigación y anima a las Partes a informar de estas acciones también en períodos de cinco años, pero de nuevo utiliza una redacción excesivamente genérica en relación con la planificación e implementación de las medidas de adaptación. Por otra parte, se trata de manera diferenciada el Mecanismo Internacional de Varsovia para las Pérdidas y Daños relaciones con las Repercusiones del Cambio Climático (especialmente los acontecimientos provocados tanto por los fenómenos extremos como por los fenómenos de evolución lenta), pero de nuevo queda para el futuro el desarrollo de sus funciones, modalidades y procedimientos. Y, más importante aún, de acuerdo 
con la Decisión de la CoP, se excluyen las cuestiones relacionadas con la responsabilidad internacional o la indemnización (par. 52).

Como conclusión puede considerarse que, desde el fracaso que supuso la Conferencia de Copenhague en 2009, hemos asistido, a lo largo de las sucesivas reuniones, a un importante esfuerzo por ir restaurando la confianza de las Partes al Convenio Marco en el proceso multilateral para el establecimiento del régimen internacional del cambio climático iniciado en 1992. En esta línea, la Conferencia de París ha constituido un nuevo punto de inflexión. La conclusión favorable de un instrumento internacional que renueve los compromisos suscritos en Kioto en 1997 y que es jurídicamente vinculante es un gran paso para la comunidad internacional. Ahora bien, el pragmatismo ha prevalecido sobre las grandes expectativas, y allí donde parecía difícil alcanzar una acción concertada de carácter multilateral, se han impuesto, bajo el manto del principio de responsabilidades comunes pero diferenciadas y la consideración de las circunstancias nacionales, las soluciones más conformes con los intereses geoestratégicos de los Estados más influyentes en el proceso de negociación, en este momento, Estados Unidos y los países del grupo BASIC. Un acuerdo, pues, que difiere de sus antecesores por su alcance limitado, que fía al futuro y a la acción de los Estados y, en menor medida, de la Conferencia de las Partes, como llegar a la limitación de los $2^{\circ} \mathrm{C}$, y que, en definitiva, se explica seguramente por la pérdida de influencia de la Unión Europea, la emergencia en el contexto de las negociaciones del grupo BASIC y la recuperación de la iniciativa por parte de Estados Unidos. 